\title{
De palavras e imagens: estigmas sociais em discursos audiovisuais ${ }^{1}$
}

\author{
Rosana de Lima Soares
}

\section{Resumo}

0 tema deste artigo localiza-se na articulação de dois campos aparentemente distantes: os discursos midiáticos, em suas formas audiovisuais, e 0 estudo da questão dos estigmas sociais. A tematização desses estigmas é um processo específico presente nas mídias, tomado aqui como objeto de estudo. Entre os objetivos do texto está apresentar como se opera, nas mídias, a construção de estigmas sociais e suas configurações predominantes, a partir de leitura e análise de discursos audiovisuais. Na primeira parte do artigo, discutimos teoricamente a questão dos estigmas sociais e algumas de suas relações com as mídias; na segunda parte, observamos as mídias para refletir sobre os estigmas sociais a partir de um conjunto de filmes, destacando a minissérie televisiva Antônia e o longa-metragem homônimo exibido nos cinemas. Ao longo do texto, a referência a jornais e revistas, 0 acompanhamento de telejornais e programas televisivos, bem como de produções cinematográficas, contribuirão para a demonstração das questões tratadas.

\section{Palavras-chave}

Mídias. Estigmas sociais. Discurso. Narrativas audiovisuais. Cinema brasileiro.

\section{Rosana de Lima Soares | rolima@usp.br}

Doutora em Ciências da Comunicação pela Escola de Comunicações e Artes da Universidade de São Paulo - ECA/USP. Professora e pesquisadora do curso de Graduação em Jornalismo e do Programa de Pós-Graduação em Ciências da Comunicação ECA/USP.

\section{Em torno dos estigmas}

0 tema deste artigo articula dois campos aparentemente distantes: os discursos midiáticos, em suas formas audiovisuais, $\mathrm{e}$ os estigmas sociais, em suas interfaces com a Psicanálise, a Antropologia, a Sociologia, a Filosofia, a linguagem, a Comunicação. Trata-se, portanto, de um trabalho que tem como objeto de estudo um aspecto específico presente nas mídias: a tematização dos estigmas sociais. Entre seus objetivos, o texto busca apresentar como se opera, nas mídias, a construção de estigmas sociais e suas configurações predominantes, a partir de leitura e análise de discursos audiovisuais.

Um breve trajeto ao redor da palavra estigma pode auxiliar no estabelecimento de parâmetros para sua compreensão, já que outras palavras podem ser a ela associadas: estereótipo, preconceito, discriminação, exclusão, minorias, dominação, problematizando as definições pressupostas em cada uma delas. Muitas vezes tomados como sinônimos, o esforço por diferenciar esses conceitos torna mais complexo 
o tema e, ao mesmo tempo, funciona como um dos parâmetros para a identificação dos estigmas sociais presentes nos discursos midiáticos.

Em sua definição, o estigma é uma cicatriz, uma marca visível (como os "estigmas da varíola"), podendo ser tanto um sinal infamante ou vergonhoso, como um sinal natural do corpo; nos dois casos, assinala uma distinção, isolando e, ao mesmo tempo, reunindo os possuidores de um mesmo atributo. Pensados a partir de sua origem religiosa, os estigmas associam-se às cinco chagas de Cristo: sua presença atesta não apenas a santidade, mas também o pertencimento a um grupo especial. Esta escolha, longe de ser um privilégio, carrega em si obrigações e distinções.

Os preconceitos, diferentemente dos estigmas, operam como julgamentos a priori realizados sobre um grupo ou um indivíduo. Podemos dizer que os estigmas, mais abrangentes, se encontram na base dos preconceitos. Estes, por sua vez, depois de serem socialmente instituídos e individualmente internalizados, passam a existir independentemente dos estigmas que os possam ter originado, naturalizando-se e, com isso, tornando-se estáveis na sociedade. Definidos pelos dicionários correntes como "conceito ou opinião formados antecipadamente, sem maior ponderação ou conhecimento dos fatos; julgamento ou opinião formada sem se levar em conta o fato que os conteste; superstição, crendice; suspeita, intolerância", os preconceitos podem gerar ódio irracional ou aversão a outras raças, credos, religiões, como percebemos frequentemente em diversas relações sociais.

Na esteira dessas intolerâncias, surgem os estereótipos, definidos usualmente como "forma compacta obtida pelo processo estereotípico", uma espécie de clichê (gravação, reprodução) que se torna um lugar-comum, um chavão utilizado sem que nos perguntemos sobre suas significações. Os discursos midiáticos, em geral, e os discursos jornalísticos, em particular, encontram-se repletos dessas expressões, que carecem de explicação. No caso dos estereótipos, ao identificar determinadas posturas ou comportamentos automaticamente enquadramos as pessoas que os possuem em categorias previamente definidas. Em relação aos estigmas, diríamos que os estereótipos funcionam como reafirmação e manutenção de um sistema já instaurado - por meio daqueles - como diferenciador de grupos determinados.

Através dos estereótipos, encaixamos as pessoas em uma forma pronta. No caso dos estigmas, trata-se de algo que 0 estigmatizado evoca em relação ao Outro, uma marca que ele possui e que, de alguma maneira, faz com que 0 outro 0 estigmatize. Podemos dizer que 0 conjunto dessas marcas sustenta 0 estereótipo e 0 preconceito. Ainda que com cautela, afirmamos

Este texto foi desenvolvido a partir da pesquisa intitulada "Mídias e estigmas sociais - Sutileza e grosseria da exclusão", realizada na Universidade de São Paulo desde março de 2003. 0 tema tem sido desenvolvido desde 0 início da pesquisa por meio de artigos em revistas e comunicações em congressos. 
que para alguém ser estigmatizado deve, de alguma forma, aceitar ocupar o lugar ao qual está sendo destinado, ver-se nele, reconhecer-se; precisa, portanto, estigmatizar-se. Nesse sentido, o estigma não passa apenas pela simples relação entre dominantes e dominados, mas por um certo consentimento e aceitação desse lugar (que se não chega a significar coesão, também não é coerção).

Outro aspecto a ser ressaltado diz respeito a uma característica que julgamos fundamental em relação aos estigmas sociais: para que operem em relação a um grupo ou indivíduo, é necessário que 0 estigmatizado (além de ser reconhecido e reconhecer-se no estigma) esteja em um lugar no qual, supostamente, não deveria estar, um lugar ao qual não pertence. É necessário que o indivíduo esteja des-locado, ou seja: é como se alguém que não devesse estar ali estivesse lá, por isso 0 incômodo e a estigmatização (exemplo ilustrativo desse des-lugar é a figura de Luiz Inácio Lula da Silva, atual presidente do Brasil em seu segundo mandato, que, tanto pela postura antes tida como radical, como pela postura hoje tida como moderada, parece sempre incomodar os outros que o estigmatizam ou os que 0 admiram - a música "Lula lá", tema da eleição de 1989, carregava em si esse deslocamento, assim como após sua primeira eleição era comum ouvirmos pessoas dizendo que "Lula chegou lá", expressão que não foi relacionada à segunda eleição do presidente).

A partir dessas operações discursivas - estigmas, preconceitos, estereótipos - chegamos aos atos cotidianos de discriminação, que isolam e segregam aqueles que carregam as marcas (os estigmas) de sua condição, excluindoos, afastando-os, desviando-os, tornando-os incompatíveis, abandonando-os, privandoos, despojando-os e, no limite, eliminandoos de fato do convívio social. Das relações de discriminação, exclusão e dominação constituem-se as minorias, ou seja, aqueles que, menos numerosos, sustentam ideias contrárias às do maior número. No caso do Brasil, como em outros países, é interessante notar que 0 estabelecimento de minorias não se faz tanto em termos numéricos, mas em termos de poder, como quando nos referimos aos negros e às mulheres como "minorias". Ainda que não representem o menor número de pessoas, as relações de dominação que os submetem são mantidas por uma suposta maioria detentora de mais poder.

0 jogo entre essas palavras se faz de forma dinâmica e não-hierárquica, ainda que possamos estabelecer uma ordem lógica: dos estigmas à dominação, passando pelos preconceitos, pelos estereótipos, pela discriminação e pela exclusão das minorias. Exemplo vivo dessas relações encontramos nos conflitos antigos e recentes no Oriente Médio (especialmente entre palestinos e israelenses), ou nas recorrentes declarações de guerra àqueles países (vindas especialmente do governo norte-americano, especialmente após os eventos ocorridos em 11 de setembro de 2001), considerando todas as nuanças que os envolvem: religião, política, economia, poder, fanatismos 
e nacionalismos de ambos os lados, sem que com isso se apaguem as relações de dominação construídas sobre fortes e visíveis estigmas.

Considerando essas observações, podemos pensar os estigmas como um campo equívoco, difuso, multifacetado e fluido; os estereótipos e preconceitos, ao contrário, constituem um campo unívoco, concêntrico, unilateral, compacto.

Entre esses dois pólos, sabemos, há toda uma escala de matizes e variações, especialmente se pensamos nas mídias: não é de maneira pura ou isolada que encontramos essas características, mas tais distinções têm, nesse momento, caráter operacional. Como exemplo, podemos citar 0 caso do personagem de história em quadrinhos "Meia Oito" (do cartunista Angeli), caricatura de um suposto militante político de esquerda: ser militante (em determinado período e para determinados atores sociais) é um estigma que, ao se transformar em desenho, agrega estereótipos, reúne características exageradas, generalizadas. Assim, o estigma pode ser pensado como uma estrutura vazada na qual vêm se encaixar os diferentes estereótipos, estes se caracterizando como uma forma cristalizada e pré-determinada.

Em geral, os estigmas trazem em sua base, sustentando-os, uma grande narrativa, ou um grande tema ao longo da história, apresentando uma certa invariância (diferenças geracionais, sexo, vida/morte, política, religião, cultura). Esse grande tema parece modificar-se pouco ao longo do tempo; o que muda são as pequenas narrativas que o recobrem, sua superfície. Alguns exemplos desses grandes temas podem ser retirados das mídias: morte (aborto, doenças, drogas, álcool, suicídio); sexo (homossexualidade, prostituição, revistas masculinas); gerações (adolescentes, jovens, crianças, idosos); religião (evangélicos, pentecostais, seitas, esoterismo); criminalidade (presídios, crime organizado, sequestros); classe social (pobreza, moradores de rua, elites); raça (negros, japoneses, brancos); saúde (obesidade, anorexia, bulimia, dietas); política (corrupção, esquerda $\mathrm{X}$ direita, partidos políticos); violência (crimes hediondos, televisão, vida urbana).

Entretanto, para verificar essa dimensão temporal estendida (invariâncias e variações) teríamos que realizar uma pesquisa que abrangesse diferentes períodos históricos, o que escapa aos objetivos do artigo.

Em outras palavras, a relação entre os estigmas e as demais expressões a eles correlatas não pode ser pensada de forma isolada; mas podemos estabelecer uma espécie de anterioridade lógica para delimitarmos nosso campo: na base dos estereótipos, preconceitos e exclusões há um estigma que os sustenta. Podemos ainda dizer que, nas três palavras citadas acima (estigmas, preconceitos, estereótipos), um indivíduo tenta encaixar o outro em um modelo pronto (deformando-0, se for preciso, para encaixálo), a partir de suas representações sociais; nos estigmas, o outro evoca em mim o desejo de estigmatizá-lo, desejo este que vem de um Outro 
lugar (nesse sentido, o estigma é sempre uma marca simbólica; mesmo que não seja visível no corpo há algo no sujeito que delimita esse campo do estigma, na relação estabelecida entre $\mathrm{eu} \leftarrow \rightarrow$ outro).

Se pudermos realizar, hipoteticamente, uma aproximação aos dois eixos de funcionamento da linguagem, diríamos que estereótipos, preconceitos e exclusões relacionam-se, sobretudo, à imagem, ao conteúdo, à figuração e, portanto, ao imaginário. Os estigmas, por sua vez, relacionam-se à forma, à origem, à estrutura - ao simbólico. 0 primeiro grupo de conceitos encontra-se, assim sendo, no eixo vertical da linguagem - 0 do significado (paradigma, sincronia, metáfora) - e o segundo conceito encontra-se no eixo horizontal - 0 do significante (sintagma, diacronia, metonímia).

Por estarem relacionados à imagem, os estereótipos, preconceitos e exclusões podem ser modificados, podemos intercambiá-los, preencher esse imaginário de diferentes formas (posso, por exemplo, enquadrar-me - e aos outros - como punk, patricinha, roqueiro etc.); e também por essa razão, em alguns casos, é possível ao indivíduo ocupar outro lugar social em relação a esses conceitos (mudando sua aparência ou características pessoais). Mas se estereótipos, preconceitos e exclusões permanecem, permanecem os estigmas. De um estigma não podemos nos separar - ele acompanhará o sujeito extensivamente -, ainda que este mude sua aparência, seu modo de vestir ou até mesmo suas ideias.

Essa afirmação, polêmica, leva-nos a uma outra característica singular dos estigmas em relação às palavras a eles correlatas: dizer que 0 indivíduo Lula tem sido constantemente estigmatizado (como falamos acima) não impede que ele tenha sido eleito, por duas vezes, presidente da República, reorganizando assim o campo entre estabelecidos e estigmatizados. 0 próprio espanto generalizado com a primeira eleição de Lula aponta para este des-lugar, para este incômodo que 0 acompanha por parecer estar onde não deveria estar (ao menos onde não esperaríamos que alguém como ele estivesse, como apontado anteriormente).

Os estigmas, portanto, não são em si negativos ou positivos (embora alguns autores, como Goffman [1978], discordem dessa afirmação, associando ao estigma a construção de uma "identidade deteriorada"), ainda que pareçam sempre mais prejudiciais do que benéficos justamente, em nossa opinião, por estarem na base de estereótipos e preconceitos. Os estigmas incluem e excluem, são dinâmicos e intercambiáveis - são multifacetados, como dissemos, e não unilaterais, como as cristalizações presentes nos estereótipos e preconceitos, determinados por modelos prévios (embora originalmente este modelo tenha tido um fundamento concreto, anterior a ele, na dinâmica social). Tais observações permitem- 
nos situar mais apropriadamente 0 campo no qual queremos transitar: os estigmas sociais.

Em tempos de ações "politicamente corretas" (presentes também nas mídias), poderíamos concluir que havia, no passado, mais discursos midiáticos claramente articulados em torno de estigmas sociais, geralmente produzindo efeitos de afirmação em relação a eles; em um momento posterior, assuntos polêmicos passaram a ser tratados de forma positivada, agregando em torno deles novos valores; recentemente, parece que alguns temas desapareceram das páginas dos jornais, como se a simples omissão dos nomes pudesse apagar sua eficácia.

0 que explica tal deslocamento? Ele representa, de alguma forma, avanço em termos de comportamentos e posturas sociais, uma diminuição de estereótipos e preconceitos? Ou trata-se apenas de uma ausência? Se há uma ausência, por quais mecanismos ela se torna presente, ou seja, quais construções discursivas articulam hoje os estigmas nas mídias? $0 u$ teríamos que concluir que não há mais a conjunção mídias e estigmas sociais? Essas são algumas das perguntas que tentaremos responder a seguir, passando dos referenciais teóricos para aspectos metodológicos que nos auxiliarão na leitura dos discursos midiáticos e na conceituação do campo dos estigmas sociais, a fim de demonstrar nossas proposições.

A dinâmica dos estigmas, da maneira como a abordaremos, recoloca em termos sociais a discussão sobre dominantes e dominados: não haveria, por um lado, os excluídos e, por outro, os dominadores, como se fossem blocos homogêneos ou verticalizados. Dentro de cada um dos diversos grupos sociais - mais apropriadamente pensados como redes - há brechas e passagens, para além de seus dualismos. Desde Gramsci (2004) sabemos que conceber o mundo como dividido apenas em dois grupos previamente conceituados não dá conta da complexidade atual, em que os lugares são reapropriados; daí um problema crucial para a sociologia hoje, relativo à dificuldade de se classificar, por exemplo, os indivíduos em classes sociais compactas. 0 conceito de estigma, nesse sentido, não se limita à oposição enunciada por Elias e Scotson (2000) entre "estabelecidos e outsiders" (ou estigmatizados), embora 0 autor esteja correto ao afirmar ser ela determinante, mas mistura e intercambia papéis, apontando para processos de hegemonias e hierarquizações dentro de cada uma das redes sociais.

Alguns exemplos presentes nas mídias podem ilustrar tal troca de lugares: nas páginas dedicadas ao jornalismo esportivo, há alguns anos, os jogadores de futebol Marcelinho Carioca (ex-jogador do Sport Clube Corinthians) e Kaká (ex-jogador do São Paulo Futebol Clube) eram, cada um a seu modo, estigmatizados. 0 primeiro, por ser considerado pelos comentaristas briguento, encrenqueiro e dissimulado, características que não deveriam fazer parte do simpático grupo dos jogadores; o segundo, por 
pertencer a um grupo que não costuma estar presente nos campos de futebol: é branco, de classe média, visto como estudioso e elegante, ou seja, está ao mesmo tempo além e aquém daquilo que é usualmente atribuído a um jogador de futebol. Outros exemplos temáticos de estigmas nas mídias podem ser apontados cotidianamente: as camisetas de futebol das torcidas organizadas; os piercings usados pelos jovens; as estrelas do PT na década de 1980-90; as ações do MST e seus atores; os papéis destinados aos latinos nos filmes americanos; as referências à síndrome de Down e à esquizofrenia em recentes novelas da Rede Globo (Páginas da vida, 2007; Caminho das Índias, 2009); o uso de drogas e suas consequências; os movimentos "antiglobalização", em que o prefixo anti já marca a posição a partir da qual uma suposta resistência se articula.

É curioso lembrar que os nomes próprios carregam, também eles, estigmas - como o caso do menino sequestrado "Pedrinho" (Pedro Rosalino Braule Pinto, filho de Jairo e Lia Braule Pinto), encontrado 17 anos depois como "Oswaldo Martins Borges Jr.", história presente no noticiário midiático (especialmente por ocasião do julgamento e condenação de sua mãe adotiva, Vilma Martins Costa, como sequestradora, em 2003) e, mais recentemente, tema da novela Senhora do destino, da Rede Globo (2004). Um outro exemplo interessante em relação aos estigmas dos nomes pode ser retirado também do futebol. 0 clube esportivo Palmeiras, de São Paulo, comumente denominado "porco" por seus torcedores, adotou como apelido um nome depreciativo que lhe foi dado pela torcida adversária. 0 estigma, negativo, deixou de sê-lo quando os próprios palmeirenses reconheceram este apelido e passaram a se autodenominar "porcos".

0 cinema também traz diversas possibilidades para pensarmos os estigmas. É o caso dos filmes do diretor norte-americano Tim Burton que, em muitos momentos, conta sua história pelo olhar dos outsiders (vilões, mendigos, deserdados), articulando suas narrativas em torno deles - lembremos, por exemplo, o filme Edward mãos de tesoura/Edward scissorhands (1990), misto de monstro e humano; Batman/ Batman (1992), em que a narrativa é contada a partir da perspectiva do antagonista Pinguim; 0 vilão sobrenatural de A lenda do cavaleiro sem cabeça/Sleepy hollow (1999); e a refilmagem de $O$ planeta dos macacos/Planet of the apes (2001), em que símios e humanos intercambiam marcas e lugares. Além dele, outro diretor norte-americano, David Lynch, move-se com desenvoltura no terreno pantanoso dos estigmas, despertando estranhamentos a cada filme (desde Veludo azul/Blue velvet, 1986; até História real/ The Straight story, 1999; e Cidade dos sonhos/ Mulholland Drive, 2001).

0 filme Gattaca: a experiência genética/Gattaca (1997), de Mike Nichols, uma ficção científica que trata das formas de controle e exclusão numa sociedade do futuro - potencializadas 
nos modos de vigilância apresentados no filme

\section{Minority report: a nova lei/Minority report}

(2002), de Steven Spielberg -, apresenta nossas marcas únicas e invisíveis (nosso DNA, nossas digitais) como forma de discriminar, isolar e separar. Tais marcas funcionam como estigmas, pois são sinais que levam ao isolamento e à diferenciação. Nesse filme, os três personagens masculinos centrais apresentam entre si claras relações de atração e repulsa, apontando para a complexidade dos estigmas. Tal complexidade pode ser percebida também no filme Stigmata/ Stigmata (1999), de Rupert Wainwright, no qual a marca que aparece no indivíduo ao mesmo tempo o faz ser percebido como santo (nos moldes dos estigmas de Cristo) e lhe impinge sofrimento (na recusa de sua condição).

Ainda tomando como referência 0 cinema, o filme Os outros/The others (2001), de Alejandro Amenábar, mostra-se como ilustrativo das relações de pertença e não-pertença estabelecidas pelos estigmas: ao intercambiar os papéis entre vivos e mortos, habitantes e intrusos, aponta de forma surpreendente para a relatividade de tais classificações. As fotos de Sebastião Salgado, trabalho que se coloca nas fronteiras entre arte e fotojornalismo, também apontam para os estigmas sociais. Nos rostos sofridos estampados nas páginas de seus livros (ou nas caras reproduções presentes em salas de jantar), vemos ao mesmo tempo tanta miséria e tanta beleza que nos sentimos, por alguma razão, incomodados.
No campo do jornalismo, jornais diários como o extinto Notícias populares especializaramse - ao menos em períodos mais recentes - em articular suas notícias em torno dos estigmas sociais. Aliados ao tom humorístico, os estigmas estampados nas páginas do $N P$ (que atendia a um segmento específico de público, supostamente das classes populares) captavam a atenção de seus leitores. De modo análogo e, na maioria das vezes, definido como "sensacionalista", 0 telejornal Aqui Agora, veiculado pela emissora SBT entre 1991 e 1997 (com uma segunda versão em 2008, exibida por menos de dois meses), e 0 mais recente Brasil Urgente, veiculado desde 2001 pela Rede Bandeirantes e apresentado por José Luiz Datena (tendo como concorrentes o Cidade Alerta, da Rede Record, e o Repórter Cidadão, da Rede TV!, ambos extintos), transpuseram para a televisão as imagens estampadas no NP. 0 que nos leva a perguntar: 0 que há, afinal, nos estigmas, que nos faz ser por eles capturados? Muitos programas televisivos utilizam-se dessa fórmula para cativar sua audiência, transmutando em imagens as marcas dos estigmas sociais.

0 que há em comum nesses exemplos é que os estigmas, de certa maneira, apontam para uma estrutura subjacente a todas as sociedades humanas - a de incluir e excluir por meio do estabelecimento de semelhanças e diferenças - e também para um dos nossos maiores desafios enquanto coletividade: saber lidar melhor com nossas singularidades e incompletudes, 
com nossas lacunas e ausências. Além disso, ao demarcar os limites entre estabelecidos e outsiders, os estigmas revelam as representações sociais de determinado grupo, apontando para seus recobrimentos históricos e culturais.

Portanto, para que a hipótese sobre a articulação mídias e estigmas sociais (qualquer que seja o substantivo que a conjugue: confirmação, construção, criação, revelação, denúncia, ou outros) seja demonstrada, é preciso trazer discursos concretos das mídias (jornais, TV, revistas, filmes, internet) e discuti-los a partir de suas especificidades. Haveria mesmo a presença de estigmas nas mídias na forma como ensaiamos? As mídias estariam, de fato, intrinsecamente articuladas a eles? Mesmo não havendo, abertamente, a presença de estigmas sociais nas mídias, estariam eles interditos (entre os ditos) de seus discursos? 0 artigo se propõe à exploração dessas questões, para comproválas (ou não) por meio de casos singulares, demonstrando-as.

Através da análise das mídias, podemos fazer os estigmas sociais - velados ou revelados emergirem, embora não se trate de buscar nas entrelinhas suas aparições; ao contrário, tratase de ver o que está no texto (entendido em sentido amplo), ou seja, os efeitos de sentido provocados pelo discurso. A impressão genérica de que os atuais discursos midiáticos parecem tratar apenas indiretamente os estigmas sociais tem respaldo em um aparente apagamento dos estigmas nas mídias, ou no seu confinamento em veículos e programas específicos. As análises aqui reunidas permitirão confrontar tal posição.

Após discutir teoricamente a questão dos estigmas sociais e algumas de suas relações com as mídias, portanto, passaremos a fazer 0 movimento inverso: olhar as mídias para refletir sobre os estigmas sociais. Acreditamos ser esta a única maneira de não nos perdermos em discussões descoladas da produção midiática. Ainda que o exercício teórico seja produtivo em si mesmo, ao tratar das mídias, é preciso voltar à realidade concreta de suas produções para delas extrair novas teorias, o que buscamos realizar na segunda parte do artigo. 0 objetivo é fazer uma ponte efetiva entre teoria e prática, sempre que possível refletindo sobre as mídias a partir das questões suscitadas pelos textos teóricos, trazendo exemplos e procurando analisar as produções midiáticas atuais. A leitura de jornais e revistas, o acompanhamento de telejornais e programas televisivos, além de produções cinematográficas, contribuirão para a demonstração das questões tratadas.

Para identificar precisamente o que aparece nos discursos midiáticos, a presença ou não de estigmas, 0 que há e o que não há em circulação nas mídias, é preciso olhar o que está sendo veiculado em seus textos e imagens, ler os textos e imagens, ver o que estão nos dizendo. Assim, esperamos poder demonstrar as relações teóricas esboçadas acima a partir de discursos 
audiovisuais selecionados para 0 artigo. Por sua característica polêmica e questionadora, os estigmas não podem ser tratados desvinculados da produção discursiva empreendida nas mídias. Um de seus paradoxos é também sua singularidade: por oposição (e dizer oposição é dizer também posição, como na linguagem) os estigmas têm a capacidade de, ao mesmo tempo em que separam (dividem, catalogam, categorizam), unir em novas combinações esses desiguais - os estigmatizados.

Ao mostrar temas presentes nas mídias, poderemos afirmar se aquilo que tratamos teoricamente em relação aos estigmas pode de fato ser confirmado (ou não) e, dessa forma, realizar uma síntese das principais características dos estigmas sociais a partir dos discursos midiáticos. Dessa forma, a análise deve observar os discursos midiáticos a fim de verificar como se apresentam neles os estigmas sociais, por meio de um exercício de acompanhamento dos mecanismos de construção discursiva na linguagem. Tratase de mostrar, fundamentalmente, por que determinado assunto ou tema pode ser caracterizado como um estigma nas mídias e como (de que forma) se dá tal caracterização. Uma questão produtiva para esse processo de análise é pensar a diferença, nas mídias, entre não poder escapar de estigmas (parte intrínseca da sociedade) e privilegiar os estigmas em seus discursos. Na base dessa reflexão, encontra-se uma de nossas preocupações principais: refletir sobre as mídias para torná-las cada vez mais próximas do que possa ser chamado um trabalho de qualidade e, porque não, de transformação. Ao assumir uma postura crítica em relação às mídias não se trata de destituí-las ou derrubálas, mas de colocá-las em crise para buscar possibilidades de ressonância.

É importante, nessa perspectiva, estabelecer uma distinção entre estigmas inerentes à sociedade - ou estigmas originais, se pudermos criar esta expressão, com seus recobrimentos históricos e culturais específicos, e também seu caráter invariante: morte, adoção, prostituição, maternidade, velhice, por exemplo - e os estigmas sociais que efetivamente aparecem nas mídias - atentando para a forma específica com que as mídias constroem discursivamente estes estigmas. 0s grupos sociais se organizam (se unem e se distinguem) a partir de estigmas (posições e oposições). Entretanto, as manifestações e hierarquizações dos estigmas nas mídias não são dadas previamente, mas apontam para processos de seleção e combinação.

Além dos exemplos, anteriormente citados, uma rápida passagem por jornais, revistas e filmes permite a identificação de temas que, em princípio, remetem aos estigmas sociais. Entre eles, podemos apontar os discursos em torno da legalização do aborto, o tabu que recobre a adoção, a dificuldade de ser um ex-detento, 0 isolamento causado pela dependência química, 
o preconceito contra as classes populares (incluindo suas crianças), o deboche em relação às pessoas religiosas (muitas vezes chamadas de "fanáticos"), as polêmicas campanhas publicitárias de algumas empresas, as imagens associadas (positiva ou negativamente) aos políticos e a seus partidos, as caracterizações de determinados grupos (sem-terra, ativistas).

A questão da aids também é tema facilmente observável quando tratamos de mídias e estigmas sociais (SOARES, 2002). Recentemente, notamos um certo desaparecimento de sua presença, sobretudo nos jornais impressos, que pode ser confirmado pelos resultados aqui apresentados. As notícias veiculadas em jornais impressos e televisivos no dia mundial de combate à aids $\left(1^{\circ}\right.$. de dezembro de 2006) confirmam uma hipótese embrionária. Ainda que a aids permaneça como questão social relevante, seu discurso nas mídias articula-se a partir de um outro lugar: não mais 0 campo social (envolvendo as problematizações em torno de direitos, preconceitos, exclusões) mas o campo médico-científico (corroborado pelas descobertas da ciência).

É no tratamento clínico, nas novas combinações de medicamentos e no posicionamento de cada um em assumir tal posição - como sujeito responsável por sua cura tanto social como clínica - que a aids encontra seu lugar, hoje, nas mídias. É também nesse novo lugar que vemos delinear-se um outro contorno para a questão dos estigmas a ela associados. Ainda que o corpo (o sexo, o sangue, a morte) mantenha-se como ponto nodal desse contorno, seu discurso não mais se articula em torno de grupos sociais (e suas marcas aparentes) mas de indivíduos (e suas marcas invisíveis). É um corpo sobretudo imaginário - e não simplesmente biológico, como prevê a medicina - que vemos ser reafirmado no deslocamento discursivo percebido nas mídias.

A constatação advinda desse exemplo aponta um aspecto espiralado dos estigmas: apesar de termos estabelecido alguns referenciais teóricos a fim de nos guiar na descrição e análise dos temas correlatos aos estigmas sociais presentes nas mídias (sobretudo para diferenciá-los de preconceitos e estereótipos), é também a partir de parâmetros anteriores à leitura das mídias que ensaiamos tais definições. Ou seja: é um percurso dedutivo e indutivo que se apresenta - partimos de uma teoria para encontrar a demonstração de seus postulados, ao mesmo tempo em que olhamos os objetos de estudo para deles extrair uma teoria.

Tal movimento pode ser percebido também em análises preliminares de filmes, etapa que amplia os limites dos discursos jornalísticos anteriormente apontados (SOARES, 2005) a outros campos de produção midiática. Inicialmente, não havíamos definido a necessidade de diferenciar filmes ficcionais e não-ficcionais. 0 aumento do número de produções documentais e as diversas formas de cruzamentos assinaladas recentemente entre 
esses dois gêneros levou-nos ao estabelecimento desta distinção, considerando tais especificidades no levantamento realizado. Em termos formais, a proximidade dos documentários (filmes de nãoficção) aos telejornais (especialmente em suas reportagens) é mais evidente, fazendo com que as narrativas ficcionais tenham sido privilegiadas neste momento, já que tratamos de discursos referenciais em artigo anterior (SOARES, 2008). Além disso, evocamos os modos de inserção de elementos factuais nas narrativas ficcionais (como em telenovelas), e também o processo inverso, de ficcionalização da realidade (como em telejornais), como um modo de apontar 0 tênue limite entre fato e fantasia nos discursos audiovisuais contemporâneos.

\section{Estigmas audiovisuais: primeiras imagens, primeiras leituras}

Como forma de ampliar nossa discussão, trataremos de filmes em longa-metragem, ficcionais ou não-ficcionais, lançados em circuito comercial. Para delimitar os filmes tratados e considerando o crescimento recente (e relevante) das produções cinematográficas brasileiras, optamos por tratar apenas de filmes nacionais. Como recorte cronológico, elegemos os anos de referência de 2003 a 2006 (momento imediatamente posterior à chamada "retomada do cinema brasileiro" e com presença significativa de público nas salas de cinema), constituindo uma amostragem não-aleatória a partir do acompanhamento dos lançamentos ocorridos nesses anos, sem uma preocupação exaustiva seja no sentido de abordar qualitativamente todos os filmes lançados, seja no sentido de explorar um conjunto completo de filmes em termos cronológicos e quantitativos. Para complementar esse período, selecionamos alguns filmes lançados em 2002 considerados relevantes para a amostragem e, de certa maneira, precursores dos filmes lançados em 2003.

No período assinalado, colecionamos um conjunto de filmes escolhidos por critérios prédeterminados. Em primeiro lugar, definimos a escolha a partir do conceito de estigmas sociais apresentado pelos elementos expostos no início do artigo; em segundo lugar, optamos por abordar filmes que representam uma tendência, no cinema brasileiro contemporâneo, em tratar de temáticas políticas e sociais, quase sempre de forma crítica e engajada; em terceiro lugar, buscamos montar um mosaico variado das produções nacionais recentes, elegendo para a análise filmes que apresentam aspectos singulares e, sobretudo, diferenciados entre si. Nos limites deste artigo, optamos não por analisar exaustivamente cada filme, mas em isolar neles aspectos que tematizam os estigmas sociais.

Na análise de produtos cinematográficos, consideramos os filmes em longa-metragem exibidos no cinema como parte integrante dos discursos midiáticos, sem com isso desconsiderar que o cinema é, também, uma atividade industrial em seus modos de produção 
e uma atividade artística em suas formas de concepção. Não realizamos uma discussão sobre essas distinções, ou sobre 0 estatuto da autoria e da narrativa no cinema, mas reconhecemos a importância desse debate. Os filmes documentais fornecem uma possibilidade diversa para pensarmos os estigmas sociais, pois utilizam elementos de referencialidade e de construção da realidade de modo semelhante ao do jornalismo sem, contudo, mimetizá-lo. De outro lado, os filmes de ficção colaboram para acrescentar novos aspectos ao tema, sobretudo por utilizarem formas narrativas específicas em seus discursos. Ainda assim, é importante

lembrar que as fronteiras entre o documental e o ficcional têm sido constantemente desafiadas, estreitando seus limites.

A partir desses elementos, apresentamos uma seleção de filmes relacionados aos estigmas sociais. Reforçamos o fato de a amostragem ter sido feita, sobretudo, a partir de uma demarcação temática no período de tempo assinalado. Apresentamos abaixo três tabelas ${ }^{2}$ contendo os títulos e as principais características dos filmes para, em seguida, destacar alguns de seus aspectos específicos ${ }^{3}$.

\begin{tabular}{|c|c|c|c|c|}
\hline \multicolumn{5}{|c|}{ TABELA I } \\
\hline FILMES DE FICÇÃO E NÃO-FICÇÃ0 (2002-2003) \\
\hline Título & Diretor & Ano & Gênero & Duração \\
\hline Cidade de Deus & Fernando Meirelles & 2002 & Ficção & $135^{\prime}$ \\
\hline Edifício Master & Eduardo Coutinho & 2002 & Documentário & $110^{\prime}$ \\
\hline Durval Discos & Anna Muylaer & 2002 & Ficção & $96^{\prime}$ \\
\hline Janela da alma & João Jardim & 2002 & Documentário & $73^{\prime}$ \\
\hline Madame Satã & Karim Aïnouz & 2002 & Ficção & $105^{\prime}$ \\
\hline 0 invasor & Beto Brant & 2002 & Ficção & $97^{\prime}$ \\
\hline Ônibus 174 & José Padilha & 2002 & Documentário & $133^{\prime}$ \\
\hline Uma onda no ar & Helvécio Ratton & 2002 & Ficção & $92^{\prime}$ \\
\hline Amarelo manga & Cláudio Assis & 2003 & Ficção & $100^{\prime}$ \\
\hline Carandiru & Hector Babenco & 2003 & Ficção & $146^{\prime}$ \\
\hline Houve uma vez dois verões & Jorge Furtado & 2003 & Ficção & $75^{\prime}$ \\
\hline 0 caminho das nuvens & Vicente Amorim & 2003 & Ficção & $100^{\prime}$ \\
\hline 0 homem do ano & José Henrique Fonseca & 2003 & Ficção & $116^{\prime}$ \\
\hline 0 homem que copiava & Jorge Furtado & 2003 & Ficção & $124 '$ \\
\hline Passaporte húngaro & Sandra Kogut & 2003 & Documentário & $71^{\prime}$ \\
\hline $1,99-$ Um supermercado que vende palavras & Marcelo Masagão & 2003 & Ficção & $72^{\prime}$ \\
\hline
\end{tabular}

Os dados constantes das tabelas foram pesquisados pela internet e a relação completa dos sites encontra-se ao final da bibliografia. Em alguns casos, artigos de jornal foram utilizados para complementar informações e dados considerados relevantes. As tabelas apresentam um grande número de filmes, tomando como critério principal sua correlação ao tema dos estigmas sociais. Notemos que a variação em termos de número de espectadores, tempo em cartaz e repercussão na crítica é bastante acentuada, trazendo desde filmes com menos de 100 mil espectadores até filmes com 5 milhões de espectadores.

Dados pesquisados em www.ancine.gov.br (lançamentos por ano). Para fichas técnicas completas, elenco, sinopses e demais informações sobre os filmes, ver www.adorocinemabrasileiro.com.br. 


\begin{tabular}{|c|c|c|c|c|}
\hline \multicolumn{5}{|c|}{$\begin{array}{c}\text { TABELA ॥ } \\
\text { FILMES DE FICÇÃO E NÃO-FICÇÃO (2004-2005) }\end{array}$} \\
\hline Título & Diretor & Ano & Gênero & Duração \\
\hline À margem da imagem & Evaldo Mocarzel & 2004 & Documentário & $72^{\prime}$ \\
\hline As filhas do vento & Joel Zito Araújo & 2004 & Ficção & $85^{\prime}$ \\
\hline Cazuza - 0 tempo não pára & Sandra Werneck e Walter Carvalho & 2004 & Ficção & 90 \\
\hline Contra todos & Roberto Moreira & 2004 & Ficção & 95 \\
\hline De passagem & Ricardo Elias & 2004 & Ficção & $87^{\prime}$ \\
\hline Entreatos & João Moreira Salles & 2004 & Documentário & $117^{\prime}$ \\
\hline Fala tu & Guilherme Coelho & 2004 & Documentário & $74^{\prime}$ \\
\hline Garotas do ABC & Carlos Reichenbach & 2004 & Ficção & 124 \\
\hline Narradores de Javé & Eliane Caffé & 2004 & Ficção & $100^{\prime}$ \\
\hline 0 outro lado da rua & Marcos Bernstein & 2004 & Ficção & $97^{\prime}$ \\
\hline 0 prisioneiro da grade de ferro & Paulo Sacramento & 2004 & Documentário & 123 \\
\hline Olga & Jayme Monjardim & 2004 & Ficção & $141^{\prime}$ \\
\hline Pelé eterno & Aníbal Massaini & 2004 & Documentário & $120^{\prime}$ \\
\hline Peões & Eduardo Coutinho & 2004 & Documentário & $85^{\prime}$ \\
\hline Redentor & Claudio Torres & 2004 & Ficção & 95 \\
\hline A pessoa é para o que nasce & Roberto Berliner & 2005 & Documentário & $84^{\prime}$ \\
\hline Brilhante & Conceição Senna & 2005 & Documentário & $75^{\prime}$ \\
\hline Cabra cega & Toni Venturi & 2005 & Ficção & $107^{\prime}$ \\
\hline Cidade baixa & Sérgio Machado & 2005 & Ficção & 93 \\
\hline Cinema, aspirinas e urubus & Marcelo Gomes & 2005 & Ficção & 90 \\
\hline Do luto à luta & Evaldo Mocarzel & 2005 & Documentário & $75^{\prime}$ \\
\hline 2 filhos de Francisco & Breno Silveira & 2005 & Ficção & $132^{\prime}$ \\
\hline Família Alcântara & Daniel e Lilian Solá Santiago & 2005 & Documentário & $56^{\prime}$ \\
\hline Garrinha - Estrela solitária & Milton Alencar & 2005 & Ficção & $110^{\prime}$ \\
\hline Meninas & Sandra Werneck & 2005 & Documentário & $71^{\prime}$ \\
\hline Meu tio matou um cara & Jorge Furtado & 2005 & Ficção & $85^{\prime}$ \\
\hline 0 fim e o princípio & Eduardo Coutinho & 2005 & Documentário & $110^{\prime}$ \\
\hline Olhar estrangeiro & Lucia Murat & 2005 & Documentário & $70^{\prime}$ \\
\hline Preto e branco & Carlos Nader & 2005 & Documentário & $74^{\prime}$ \\
\hline Pro dia nascer feliz & João Jardim & 2005 & Documentário & 88 \\
\hline Quanto vale ou é por quilo? & Sérgio Bianchi & 2005 & Ficção & $104^{\prime}$ \\
\hline Quase dois irmãos & Lucia Murat & 2005 & Ficção & $102 '$ \\
\hline Vlado: 30 anos depois & João Batista de Andrade & 2005 & Documentário & $90^{\prime}$ \\
\hline
\end{tabular}




\begin{tabular}{|c|c|c|c|c|}
\hline \multicolumn{5}{|c|}{$\begin{array}{c}\text { TABELA III } \\
\text { FILMES DE FICÇÃO E NÃO-FICÇÃO (2006) }\end{array}$} \\
\hline Título & Diretor & Ano & Gênero & Duração \\
\hline 1972 & José Emílio Rondeau & 2006 & Ficção & $100^{\prime}$ \\
\hline A concepção & José Eduardo Belmonte & 2006 & Ficção & $96^{\prime}$ \\
\hline À margem do concreto & Evaldo Mocarzel & 2006 & Documentário & $85^{\prime}$ \\
\hline Achados e perdidos & José Joffily & 2006 & Ficção & $100^{\prime}$ \\
\hline Anjos do sol & Rudi Lagemann & 2006 & Ficção & $92^{\prime}$ \\
\hline Antônia & Tata Amaral & 2006 & Ficção & $90^{\prime}$ \\
\hline Árido movie & Lírio Ferreira & 2006 & Ficção & $115^{\prime}$ \\
\hline Boleiros 2 - Vencedores e vencidos & Ugo Giorgetti & 2006 & Ficção & $86^{\prime}$ \\
\hline Brasília $18 \%$ & Nelson Pereira dos Santos & 2006 & Ficção & $102 '$ \\
\hline Cafundó & Paulo Betti e Clóvis Bueno & 2006 & Ficção & $101^{\prime}$ \\
\hline Cafuné & Bruno Vianna & 2006 & Ficção & $73^{\prime}$ \\
\hline Crime delicado & Beto Brant & 2006 & Ficção & $87^{\prime}$ \\
\hline Estamira & Marcos Prado & 2006 & Documentário & $115^{\prime}$ \\
\hline Eu me lembro & Edgard Navarro & 2006 & Ficção & 108 \\
\hline Falcão - Meninos do tráfico & $\begin{array}{l}\text { MV Bill, Celso Athayde e } \\
\text { Centro de Audiovisual da } \\
\text { Central Única das Favelas }\end{array}$ & 2006 & Documentário & 62 \\
\hline Intervalo clandestino & Eryk Rocha & 2006 & Documentário & $95^{\prime}$ \\
\hline Mulheres do Brasil & Malu Martino & 2006 & Ficção & 113' \\
\hline No meio da rua & Antonio Carlos Fontoura & 2006 & Ficção & $89^{\prime}$ \\
\hline $\begin{array}{l}0 \text { ano em que meus pais saíram de } \\
\text { férias }\end{array}$ & Cao Hamburger & 2006 & Ficção & $110^{\prime}$ \\
\hline 0 céu de Suely & Karim Aïnouz & 2006 & Ficção & $88^{\prime}$ \\
\hline 0 maior amor do mundo & Carlos Diegues & 2006 & Ficção & 106 \\
\hline 0 Sol - Caminhando contra 0 vento & Tetê Moraes & 2006 & Documentário & $90^{\prime}$ \\
\hline Os doze trabalhos & Ricardo Elias & 2006 & Ficção & $90^{\prime}$ \\
\hline 0 passageiro: segredos de adulto & Flávio Tambellini & 2006 & Ficção & $105^{\prime}$ \\
\hline Zuzu Angel & Sergio Rezende & 2006 & Ficção & 103 \\
\hline
\end{tabular}

As tabelas apresentam uma lista abrangente de filmes pertinentes à questão dos estigmas sociais articulados em discursos audiovisuais. Explorar cada um deles em suas características verbais e visuais exigiria um espaço muito maior do que aquele previsto neste artigo, assim como estabelecer subclassificações e categorias específicas de análise avançaria além de nosso propósito neste momento.

Se notarmos os dados compilados pelo site Filme $\mathrm{B}$, temos que
[...] de 1995 (ano tido como marco do início da retomada do cinema nacional) até 2003, estrearam uma média de 23 títulos nacionais por ano. Em 2004 esse número pulou para 47 filmes. Se em 2005 houve um leve recuo para 39 estréias, apenas no primeiro semestre de 2006 já foram lançados 31 filmes nacionais. Com mais 27 estréias previstas até 0 final do ano totalizaríamos um recorde no período: 58 estréias brasileiras em salas de cinema. ${ }^{4}$

Se tomarmos os totais apresentados nas tabelas, a saber: oito títulos em 2002; oito títulos em 2003; 15 títulos em 2004; 18 títulos em 2005; e 25 
títulos em 2006, veremos que o número de filmes é significativo (74). Em 2004 e 2006, temos um pouco menos da metade dos lançamentos relacionados, e, em 2005, temos exatamente a metade.

Uma das questões que nos colocamos nesse momento é sobre 0 significado desses números. 0 que sinalizam em relação ao cinema brasileiro? Em princípio, acreditamos que a forte tônica em filmes políticos e de crítica social já determina sua vinculação ao tema dos estigmas sociais. De maneira mais ou menos direta, grande parte dos filmes brasileiros (com exceção, no caso da amostragem, de comédias, comédias românticas, filmes de época, adaptações literárias, filmes experimentais) tematiza, de algum modo, questões relativas aos estigmas, seja por meio da referência direta à realidade brasileira (tida como desigual e excludente, apresentando conflitos econômicos e sociais de toda espécie), seja por meio do questionamento de como se destacar desta mesma realidade (tendo como princípio a mudança nos modos de ser e estar, a busca por outras maneiras de existir e agir). Oscilando entre os limites daquilo que chamamos de estigmas de reforço e/ou estigmas de transposição, acreditamos que o filme Antônia torna-se emblemático em relação à construção de estigmas sociais em discursos audiovisuais.

No ano de 2006, foi lançada uma minissérie televisiva chamada Antônia, uma co-produção entre 02 (produtora de Fernando Meirelles) e Globo Filmes. Veiculada na Rede Globo em cinco episódios ${ }^{5}$ às sextas feiras, após a programação em horário nobre da Globo, a minissérie atingiu 32 pontos no Ibope (número considerado alto para o horário). Além da própria minissérie, a divulgação do filme naquele momento foi intensa, com a participação das atrizescantoras em diversos programas da emissora, antecedendo o lançamento do filme em longametragem de Tata Amaral. 0 bom desempenho televisivo levou a uma expectativa elevada de público para a estreia no cinema: diretora e produtores esperavam que 0 filme chegasse a 500 mil espectadores e, nas primeiras quatro semanas, o número estava em pouco mais de 75 mil, muito abaixo do necessário para atingir a meta inicialmente prevista ${ }^{6}$.

Os episódios televisivos de Antônia foram exibidos em 17/11, 24/11, 01/12, 08/12 e 15/12/2006. Ambientada no bairro Brasilândia, na periferia de São Paulo, a minissérie foi baseada no longa-metragem de Tata Amaral e lançada na televisão antes de o longa-metragem estrear nos cinemas (09/02/2007). Todas as atrizes-cantoras possuem trabalhos musicais anteriores ou posteriores à minissérie, que teve roteiros escritos por autores diferentes a cada episódio, entre eles: Elena Soárez, Fernando Meirelles, Jorge Furtado, Claudia Tajes e a própria Tata Amaral (informações: www.globo.com/antonia).

Conforme matéria publicada no jornal Folha de S. Paulo em 12/03/2007, intitulada "Antônia - Por que o filme não brilhou" (uma alusão à música tema, cujo refrão diz "Antônia brilha..."), outras minisséries televisivas originaram filmes de grande bilheteria. 0 último deles foi A grande família, quem em pouco mais de um mês já havia levado quase 2 milhões de pessoas ao cinema. Ainda assim, uma observação faz-se necessária: a ideia de que o sucesso (ou a qualidade) de um filme se mede por sua audiência pode ser questionada, revelando, ela própria, um estigma que cerca as produções nacionais. 0 fato de Antônia ter tido menos público do que 0 esperado não deveria significar, necessariamente, que fracassou enquanto filme. Mas pode apontar, em nosso ponto de vista, para um espaço de arejamento e abertura advindo de uma produção diferenciada e que rompe com os padrões usuais nas formas de tratar a periferia. As diferenças entre espectadores de televisão e cinema também devem ser consideradas nesse debate. 
A história (minissérie e filme) relata a vida de quatro amigas - Preta, Barbarah, Mayah, Lena, representadas por Negra Li, Leilah Moreno, Quelynah e Cindy Mendes -, "diferentes em suas personalidades mas iguais no sonho, lutando contra o preconceito em meio à cultura hip-hop e tentando mostrar seu talento por meio de uma atitude corajosa e batalhadora" Buscando sobreviver fazendo aquilo que mais gostam - cantar - as quatro mulheres formam 0 grupo musical "Antônia", sem nenhum recurso financeiro para sua produção e divulgação, e tentam torná-lo possível em meio a suas rotinas de trabalho, desemprego, falta de dinheiro, filhos, namorados, família. 0 filme Antônia encontra pontos de cruzamento com o filme Uma onda no ar (2002), justamente por se distanciar de uma narrativa (verbal, visual) como aquela encontrada em Cidade de Deus (2002), tida como mais recorrente quando observamos as maneiras pelas quais os estigmas sociais são apresentados em filmes de ficção ou não-ficção.

\section{Em Antônia, temos a tematização e} figurativização de estigmas de transposição, mostrando a vida da periferia em suas dificuldades e problemas sociais - violência, desemprego, machismo, pobreza -, mas também num sentido positivo - são as casas e cotidianos de pessoas comuns que vemos ali, tentando buscar soluções e não necessariamente convivendo o tempo todo apenas com aspectos conflituosos e negativos de seu cotidiano. Há, desse modo, a perspectiva transformadora - ou ao menos problematizadora - que definimos anteriormente em relação aos estigmas. Ao apontar justamente para aquilo que aparece fora do lugar, desestabilizando preconceitos e estereótipos antes arraigados na sociedade; os estigmas podem levar à recolocação desses lugares, intercambiando posições entre os diversos atores sociais para, num segundo momento, fixá-las de outra maneira. A posterior fixação pode levar a outros preconceitos e estereótipos, já que as relações sociais são pautadas por padrões que atribuem os limites entre o que é considerado "norma" ou "desvio" (FOUCAULT, 2002) em uma determinada cultura; entretanto, pode também estabelecer um questionamento das formas sustentadoras de tais lugares cristalizados, mobilizando novos atores sociais.

Talvez por isso o filme, a exemplo de Uma onda no ar, tenha tido pouca bilheteria em relação a outros modos de construção de estigmas sociais no cinema ${ }^{8}$ : ao mostrar o lado positivo e criativo da periferia - que aproximaria os seus supostos "eles" de "nós" (a classe média)-,Antônia afasta o público desta mesma classe média dos 
cinemas, talvez mais interessado - ou habituado - a ver nas telas apenas elementos verbais e visuais que reforçam os estigmas, preconceitos e estereótipos presentes em nosso imaginário (e de forma alguma isso é por nós considerado algo menos importante do que seu inverso, mas demarca um campo de reiteração em relação aos estigmas sociais). Ou seja: ao assistir filmes sobre a periferia e as temáticas sociais neles presentes - enfoque que vem se tornando cada vez mais presente no cinema -, são os aspectos evidentemente negativos e distintos de nossa própria condição social que esperamos encontrar nas telas, como podemos observar em diversos filmes apontados nas tabelas acima.

Filmes que problematizam as relações entre centro e periferia, ricos e pobres, dominantes e dominados - ou outras terminologias comuns em estudos sociológicos - tendem a ter menos público (considerando que o critério de bilheteria é fator importante na consolidação do cinema brasileiro, ainda carente de uma variedade de gêneros narrativos, como já vemos no cinema norte-americano). Desse ponto de vista, Antônia não representa propriamente um "fracasso" de bilheteria, como afirmaram alguns de seus críticos, mas de certa forma pode ter sido superestimado por se confundir, na superfície, com a abordagem social e política feita por outros filmes situados na tematização da periferia ou na proposição de alguma forma de denúncia social. Ao deslocar as posições usualmente ocupadas pela periferia e trazê- las ao centro, aproximando os estabelecidos dos estigmatizados, filmes como Antônia acabam perdendo seu lugar: não reforçam nosso imaginário sobre eles, os "outros", mas também não fazem com que estes outros se integrem ao sistema hegemônico de produção cultural.

Finalmente, gostaríamos de enfatizar que o tema dos estigmas sociais tem despertado em nós um interesse cada vez mais marcante. A cada etapa percorrida - seja em termos de estudos teóricos, seja em termos de análises das mídias - deparamo-nos com novas inquietações e configurações possíveis, obrigando-nos a rever conceitos e métodos. Além disso, trata-se de tema em expansão também nas pesquisas acadêmicas. Exemplo disso são os estudos, cada vez mais difundidos, sobre as identificações (ou identidades sociais) e suas correlações com os discursos midiáticos, bem como aqueles que tratam de temas envolvendo preconceitos ou estereótipos.

Um outro tema tem ganhado fôlego nas pesquisas em comunicação, apoiado, sobretudo, pelos estudos culturais e pela psicanálise: as complexas relações envolvendo a dinâmica social do convívio entre cada um e os outros (como vimos em alguns autores citados acima) e os conflitos daí decorrentes, indissociáveis da própria sociedade em que estão inseridos. As chamadas "figuras de alteridade" (PRADO, 2004) presentes nos discursos midiáticos sinalizam, de maneira privilegiada, pontos de confluência e de demarcação dos estigmas sociais. É sempre, 
portanto, em relação a um "outro" diferente do "mesmo" (e supostamente inferiorizado na dinâmica social), que os estigmas se articulam e apontam suas especificidades (PRADO, 2004).

É interessante notar que em relação aos estigmas sociais podemos acompanhar, mesmo antes da leitura das mídias, alguns temas recorrentes - como se uma dinâmica regular (repetição e diferença) acompanhasse tais tematizações. Entre eles, podemos citar nos atuais relatos midiáticos o Movimento dos Sem-Terra (MST), as questões de gênero (especialmente aquelas relacionadas às mulheres e aos homossexuais), os assuntos relativos ao movimento negro ou questões raciais, o mundo árabe (e, por decorrência, as ações terroristas a ele associadas), o tráfico de drogas. Ao observar nossa amostragem, podemos perceber a incidência desses temas em diferentes acepções.

Dessa forma, ao chegarmos aos discursos midiáticos audiovisuais, especialmente em filmes de longa-metragem exibidos nos cinemas, encontramos um ponto que, mais do que conclusivo, torna-se início de novas indagações, ampliando as reflexões aqui apresentadas. Observando os filmes destacados, vemos que a temática dos estigmas sociais pode ser problematizada sob uma vertente antes insuspeitada: ao tomarmos os conceitos de redundância e ressonância, referimo-nos justamente à variação (e não se trata, neste caso, de oposição entre eles) entre estigmas de reforço e/ou de transposição. Esta diferença não estava demarcada antes da análise dos filmes, levando-nos à conclusão de que muitos outros discursos midiáticos realizam em graus maiores ou menores o movimento entre esses dois pólos complementares, e de forma alguma antagônicos. Mais do que uma distinção, redundância e ressonância podem ser pensadas como processos de construção de imaginários e identidades sociais.

Entre os discursos midiáticos que contribuem para consolidar ou criar novas imagens sobre os estigmas sociais, notamos as diferentes encenações de seus temas e personagens, as ausências e presenças colocadas na narrativa e as demarcações de identidades e diferenças, como nos filmes brasileiros da última década.

Percorrendo jornais, revistas, telejornais e filmes, observamos, nesses discursos, um alto grau de redundância e de manutenção dos lugares sociais estabelecidos. Os estigmas de reforço operam como marcadores desses lugares, articulando narrativas que se repetem mesmo entre diferentes veículos e produtos midiáticos. Os estigmas de transposição relutam entre as brechas deixadas pelos discursos dominantes, pulsando como possibilidades de deslocamento dessas narrativas reiteradas. No caso do cinema, notamos que seus discursos revelam graus maiores de ressonância, apresentando espaços de passagem, oferecendo aberturas. No campo de produção dos discursos audiovisuais, nem todos os filmes poderiam ser facilmente 
definidos como pertencentes a um ou outro lugar, mas há em cada um deles traços e formas narrativas predominantes que apontam para esse movimento de reforço e/ou transposição.

Considerando a ficção como elemento articulador de qualquer forma narrativa, a tematização dos estigmas sociais em discursos audiovisuais se faz de modo transversal. Na variedade de suas formas verbais e imagéticas, esperamos ter entreaberto os espaços de passagem entre consolidação e transgressão dos estigmas nas mídias. Ao sintetizar os principais resultados encontrados em nossas análises, esperamos ainda ter demonstrado a importância dos discursos midiáticos na compreensão da problemática dos estigmas sociais, possibilitando a descoberta de caminhos que apontem bifurcações e deslocamentos em sua abordagem. Ou seja: para além da assunção de que as mídias, em suas variadas manifestações, operam como lugar de reforço dos estigmas, parece-nos que uma outra possibilidade se vislumbra: a de nelas encontrar a transposição (ruptura) de estigmas sociais.

\section{Referências bibliográficas}

AUMONT, Jacques. et al. A estética do filme.

Campinas: Papirus, 1995.

BHABHA, Homi K. 0 local da cultura. 2. reimp. Belo Horizonte: UFMG, 2003.

CERTEAU, Michel de. A cultura no plural Campinas: Papirus, 1995.

COSTA, António. Compreender o cinema. 2. ed. São Paulo: Globo, 1989.
DERRIDA, Jacques. Positions. Chicago: University of Chicago Press, 1981.

ELIAS, Norbert; SCOTSON, John L. Os estabelecidos e os outsiders. Rio de Janeiro: Jorge Zahar, 2000.

FOUCAULT, Michel. História da loucura. 6. ed. São

Paulo: Perspectiva, 2002.

FOSTER, Hal. Recodings New York: The New Press, 1985. FREUD, Sigmund. 0 mal estar na civilização. Rio de Janeiro: Imago, 1974. (Obras completas, vol. XXI)

GOFFMAN, Erving. Estigma. 2a ed. Rio de Janeiro: Jorge Zahar, 1978.

GRAMSCI, Antonio. Cadernos do cárcere. vol. 1. Rio de Janeiro: Civilização Brasileira, 2004.

HALL, Stuart. Da diáspora - Identidades e mediações culturais. Belo Horizonte: UFMG, 2003.

LACAN, Jacques. Os quatro conceitos fundamentais da psicanálise. 0 seminário. Livro XI. 4. ed. Rio de Janeiro: Jorge Zahar, 1990.

MAZZARA, Bruno M. Estereotipos e prejuicios. Madri: Acento Editorial, 1999.

PRAD0, José Luiz Aidar. A invenção do Outro na mídia semanal: por uma ética do leitor infiel. Projeto de Pesquisa/CNPq, 2004. (mimeo.)

SAID, Edward. Covering Islam. New York: Pantheon Books, 1981.

SANTIAGO, Silviano. 0 cosmopolitismo do pobre. Belo Horizonte: UFMG, 2004.

SILVA, Tomaz Tadeu da (org.). Identidade e diferença. Petrópolis: Vozes, 2000.

SOARES, R. L. Estigmas da Aids: em busca da cura. Impulso - Revista de Ciências Sociais e Humanas, Piracicaba, n. 33, p. 41-56, 2002. . Narrativas da notícia: jornalismo e estigmas sociais. Animus, Santa Maria, vol. III, n.1, p. 50-62, 2005. 
Comunicación entre culturas: el

cine brasileño y los estigmas sociales. Signo y

Pensamiento, Bogotá, v.XXIV, n. 46, p. 111-124, 2006.

Mídias e estigmas sociais: narrativas

audiovisuais em telejornais diários. Ciberlegenda, Rio

de Janeiro, ano 10, n. 20, jun. de 2008. Disponível em:

www.uff.br/ciberlegenda.

SPIVAK, G. C. Can the subaltern speak?. In: NELSON, C. \& GROSSBERG, L. (eds.). Marxism and the

interpretation of culture. London: Macmillan, 1988.

\section{Webgrafia}

www.adorocinema.com.br

www.adorocinemabrasileiro.com.br

www.cidadeinternet.com.br

www.filmeb.com.br

www.imdb.com

www.interfilmes.com

www.revistacinetica.com.br

http://www2.uol.com.br/umaondanoar/filme/

apresentacao_01.html

http://cidadededeus.globo.com/ 


\section{Of words and images: social stigmas in audiovisual discourses}

\section{Abstract}

This paper bonds two apparently parted fields: media discourses, specifically in the audiovisual segment, and social stigmas. The present article, thus, takes as object of study such particular process present in the media, social stigmas thematization. It aims to present how, in the media, social stigmas are built and also to investigate its preponderant formations, from the reading and analysis of audiovisual discourses. At first, the article discusses the theory involving social stigmas and some of their relations with the media; in a second moment our attention is turned to the media itself in order to ponder about social stigmas according to the analyzed movies. Throughout the text references extracted from the observation of newspapers and magazines, television news and television shows in general contribute to develop the issues posed.

\section{Keywords}

Media. Social stigmas. Discourse. Audiovisual narrative. Brazilian cinema.

\section{De palabras e imágenes: estigmas sociales en discursos audiovisuales}

\section{Resumen}

La temática de este texto articula dos campos aparentemente lejanos: el de los discursos mediáticos, en sus formas audiovisuales, y el de los estigmas sociales. Se toma, así, como objeto de estudio un aspecto específico de los medios: la presencia y formas de los estigmas sociales. Entre sus objetivos está presentar como se opera la construcción de los estigmas sociales en los media y cuales son sus configuraciones predominantes partiendo de la lectura y del análisis de discursos audiovisuales. Primero, presentamos teóricamente el problema de los estigmas sociales y algunas de sus relaciones con los media. Segundo, miramos a los media para reflexionar sobre los estigmas sociales recurriendo a los filmes analizados. En el texto vemos referencias a la lectura de periódicos y revistas, a la observación de periódicos y programas televisivos, así como producciones cinematográficas contribuyendo para tratar las cuestiones investigadas.

\section{Palabras clave}

Medios. Estigmas sociales. Discurso. Narrativas audiovisuales. Cine brasileño. 


\section{Expediente}

A revista E-Compós é a publicação científica em formato eletrônico da Associação Nacional dos Programas de Pós-Graduação em Comunicação (Compós). Lançada em 2004, tem como principal finalidade difundir a produção acadêmica de pesquisadores da área de Comunicação, inseridos em instituições do Brasil e do exterior.
E-COMPÓS I www.e-compos.org.br I E-ISSN 1808-2599

Revista da Associação Nacional dos Programas de Pós-Graduação em Comunicação. Brasília, v.12, n.1, jan./abr. 2009.

A identificação das edições, a partir de 2008 passa a ser volume anual com três números.

\section{CONSELHO EDITORIAL}

\section{Afonso Albuquerque}

Universidade Federal Fluminense, Brasil

Alberto Carlos Augusto Klein

Universidade Estadual de Londrina, Brasi

Alex Fernando Teixeira Primo

Universidade Federal do Rio Grande do Sul, Brasil

\section{Alfredo Vizeu}

Universidade Federal de Pernambuco, Brasil

Ana Carolina Damboriarena Escosteguy

Pontifícia Universidade Católica do Rio Grande do Sul, Bras

Ana Silvia Lopes Davi Médola

Universidade Estadual Paulista, Brasil

André Luiz Martins Lemos

Universidade Federal da Bahia, Brasil

Ângela Freire Prysthon

Universidade Federal de Pernambuco, Brasil

Antônio Fausto Neto

Universidade do Vale do Rio dos Sinos, Brasil

Antonio Carlos Hohlfeldt

Pontifícia Universidade Católica do Rio Grande do Sul, Brasil

Arlindo Ribeiro Machado

Universidade de São Paulo, Brasil

César Geraldo Guimarães

Universidade Federal de Minas Gerais, Brasil

Cristiane Freitas Gutfreind

Pontifícia Universidade Católica do Rio Grande do Sul, Brasil

Denilson Lopes

Universidade Federal do Rio de Janeiro, Brasil

Eduardo Peñuela Cañizal

Universidade Paulista, Brasi

Erick Felinto de Oliveira

Universidade do Estado do Rio de Janeiro, Brasil

Francisco Menezes Martins

Universidade Tuiuti do Paraná, Brasil

Gelson Santana

Universidade Anhembi/Morumbi, Brasi

Hector Ospina

Universidad de Manizales, Colômbia

leda Tucherman

Universidade Federal do Rio de Janeiro, Brasil

Itania Maria Mota Gomes

Universidade Federal da Bahia, Brasil

Janice Caiafa

Universidade Federal do Rio de Janeiro, Brasil

Jeder Silveira Janotti Junior

Universidade Federal da Bahia, Brasil

\section{João Freire Filho}

Universidade Federal do Rio de Janeiro, Brasil

John DH Downing

University of Texas at Austin, Estados Unidos

José Luiz Aidar Prado

Pontifícia Universidade Católica de São Paulo, Brasil

José Luiz Warren Jardim Gomes Braga

Universidade do Vale do Rio dos Sinos, Brasil

Juremir Machado da Silva

Pontifícia Universidade Católica do Rio Grande do Sul, Brasil

Lorraine Leu

University of Bristol, Grã-Bretanha

Luiz Claudio Martino

Universidade de Brasília, Brasil

Maria Immacolata Vassallo de Lopes

Universidade de São Paulo, Brasil

Maria Lucia Santaella

Pontifícia Universidade Católica de São Paulo, Brasil

Mauro Pereira Porto

Tulane University, Estados Unidos

Muniz Sodre de Araujo Cabral

Universidade Federal do Rio de Janeiro, Brasil

Nilda Aparecida Jacks

Universidade Federal do Rio Grande do Sul, Brasil

Paulo Roberto Gibaldi Vaz

Universidade Federal do Rio de Janeiro, Brasil

Renato Cordeiro Gomes

Pontifícia Universidade Católica do Rio de Janeiro, Brasil

Ronaldo George Hela

Universidade do Estado do Rio de Janeiro, Brasil

Rosana de Lima Soares

Universidade de São Paulo, Brasil

Rossana Reguillo

Instituto Tecnológico y de Estudios Superiores do Occidente, México

Rousiley Celi Moreira Maia

Universidade Federal de Minas Gerais, Brasil

Sebastião Carlos de Morais Squirra

Universidade Metodista de São Paulo, Brasi

Simone Maria Andrade Pereira de Sá

Universidade Federal Fluminense, Brasil

Suzete Venturelli

Universidade de Brasília, Brasil

Valério Cruz Brittos

Universidade do Vale do Rio dos Sinos, Brasil

Veneza Mayora Ronsini

Universidade Federal de Santa Maria, Brasil

Vera Regina Veiga França

Universidade Federal de Minas Gerais, Brasil
COMISSÃO EDITORIAL

Ana Gruszynski I Universidade Federal do Rio Grande do Sul, Brasil

Rose Melo Rocha I Escola Superior de Propaganda e Marketing, Brasil

CONSULTORES AD HOC

Alberto Schneider I Visitante Tokyo University

Alexandre Rocha da Silva I Universidade Federal do Rio Grande do Sul, Brasil

Fernanda Bruno I Universidade Federal do Rio de Janeiro, Brasil

Ida Stumpf I Universidade Federal do Rio Grande do Sul, Brasil

Kati Caetano I Universidade Tuiuti do Paraná, Brasil

Laura Cánepa I Universidade Anhembi Morumbi, Brasi

Malena Contrera I Universidade Paulista, Brasil

Sandra Gonçalves I Universidade Federal do Rio Grande do Sul, Brasil

Vicente Gosciola I Universidade Anhembi Morumbi, Brasil

REVISÃO DE TEXTO E TRADUÇÃO I Everton Cardoso

EDITORAÇ̃̃o ELETRÔNICA I Raquel Castedo
COMPós I www.compos.org.br

Associação Nacional dos Programas de Pós-Graduação em Comunicação

Presidente

Erick Felinto de Oliveira

Universidade do Estado do Rio de Janeiro, Brasil erickfelinto@uol.com.br

Vice-presidente

Ana Silvia Lopes Davi Médola

Universidade Estadual Paulista, Brasil

asilvia@faac.unesp.br

Secretária-Geral

Denize Correa Araújo

Universidade Tuiuti do Paraná, Brasil

denizearaujo@hotmail.com 